Article

\title{
Terbium-Tetracarboxylate Framework as a Luminescent Probe for the Selective Detection of Nitrofurazone
}

\author{
Qipeng $\mathrm{Li}^{1}{ }^{1}$, Yanqiong Shen ${ }^{2, *}$, Junsong Zhao ${ }^{1}$, Zejun Zhang ${ }^{1}$ and Jinjie Qian ${ }^{3, *}$ (i) \\ 1 Science and Technology Department, College of Chemistry and Chemical Engineering, Zhaotong University, \\ Zhaotong 657000, China; liqipeng10@mails.ucas.ac.cn (Q.L.); zhaojunsong5@gmail.com (J.Z.); \\ zhangzejun99@yeah.net (Z.Z.) \\ 2 Green Food Development Center of Zhaotong, Zhaotong, 657000, China \\ 3 College of Chemistry and Materials Engineering, Wenzhou University, Wenzhou 325035, China \\ * Correspondence: shenyanqiong@foxmail.com (Y.S.); jinjieqian@wzu.edu.cn (J.Q.)
}

Received: 27 February 2020; Accepted: 17 March 2020; Published: 20 March 2020

check for updates

\begin{abstract}
A novel terbium-tetracarboxylate framework with the 5,5'-(diazene-1,2-iyl)diisophthalic acid $\left(\mathrm{H}_{4}\right.$ abtc) ligand, formulated as $\left[\mathrm{Tb}(\mathrm{Habtc})(\mathrm{DMSO})\left(\mathrm{H}_{2} \mathrm{O}\right)_{2}\right]_{n}$ (ZTU-5), has been synthesized and structurally characterized. ZTU-5 features a 2D-layered structure constructed by the binuclear terbium secondary building units (SBUs) and abtc ${ }^{4-}$ ligand, which can be further expanded into a 3D-supramolecular framework by the hydrogen bond interactions. In addition, the magnetic and fluorescence properties of ZTU-5 are investigated and ZTU-5 exhibits highly selective and sensitive detection of nitrofurazone (NZF).
\end{abstract}

Keywords: terbium-tetracarboxylate framework; luminescent probe; selective detection of NZF

\section{Introduction}

Antibiotics are widely used as the specific drug for treating bacterial infection in humans and animals, while the abuse of antibiotics has caused the high levels of antibiotic residues in surface and groundwater as well as in drinking water [1-3]. Owing to the antibiotic wastewaters being highly poisonous and difficult to degrade, monitoring of antibiotic wastewaters was significant, but challenging [4,5]. Compared with the traditional detection method of antibiotics using instrumental methods such as liquid chromatography (LC), capillary electrophoresis (CE), liquid chromatography mass spectrometry (LC-MS), Raman spectroscopy (RS), ion mobility spectrometry (IMS), and so forth, the metal organic frameworks (MOFs) used as luminescent probes for the selective detection of antibiotics has been considered as a very effective and proven technology [6-11]. Despite some successes, the design and discovery of new MOFs as luminescent probes for highly selective and sensitive detection of antibiotics is also challenging and of great significance [12-15].

Hence, we have successfully constructed one novel terbium-tetracarboxylate framework with the $\mathrm{H}_{4}$ abtc ligand, formulated as [Tb(Habtc)(DMSO) $\left.\left(\mathrm{H}_{2} \mathrm{O}\right)_{2}\right]_{n}$ (ZTU-5), which features a 2D-layered structure constructed by the binuclear terbium secondary building units (SBUs) and abtc ${ }^{4-}$ ligand, which further expands into a 3D-supramolecular framework by the hydrogen bond interactions. Herein, its syntheses, crystal structures, and magnetic and fluorescence properties are discussed in detail.

\section{Experimental}

\subsection{Materials and Methods}

All the chemical reagents were commercially purchased and used without further purification. The powder X-ray diffraction (XRD) patterns were recorded on crushed single crystals in the $2 \theta$ 
range of $5 \sim 50^{\circ}$ using $\mathrm{Cu}-K \alpha(1.5418 \AA)$ radiation. Elemental analyses $(\mathrm{C}, \mathrm{H}$, and $\mathrm{N})$ were measured with an Elementar Vario EL III Analyzer (Elementar, Germany). Magnetic susceptibility data were collected on a Quantum Design MPMS (SQUID)-XL magnetometer (Quantum Design, United States). Fluorescence spectra, quantum yield $(\Phi)$, and lifetime for ZTU-5 were performed on an Edinburgh Analytical instrument (FLS920) (Edinburgh Instruments, United Kingdom) with both continuous $(450 \mathrm{~W})$ and pulsed Xenon lamps.

\subsection{Synthesis of $\mathbf{Z T U}-\mathbf{5}$}

A mixture of $\mathrm{Tb}\left(\mathrm{NO}_{3}\right)_{3} \cdot 6 \mathrm{H}_{2} \mathrm{O}(0.25 \mathrm{mmol}, 113.26 \mathrm{mg})$ and $\mathrm{H}_{4}$ abtc ligand $(0.25 \mathrm{mmol}, 89.57 \mathrm{mg})$ was placed in a $25 \mathrm{~mL}$ Teflon-lined stainless steel vessel with $6 \mathrm{~mL}$ of $\mathrm{DMSO} / \mathrm{H}_{2} \mathrm{O}(\mathrm{V} / \mathrm{V}=1: 1)$. The mixtures were heated to $120{ }^{\circ} \mathrm{C}$ over $4 \mathrm{~h}$, kept at this temperature for three days, and then cooled to room temperature during another two days. White crystals of ZTU- 5 were obtained in $42 \%$ yield based on $\mathrm{Tb}\left(\mathrm{NO}_{3}\right)_{3} \cdot 6 \mathrm{H}_{2} \mathrm{O}$. Anal. Calcd. for ZTU-5: C, 34.41; H, 2.73; N, 4.46\%. Found: C, 34.48; H, 4.77; N, $4.38 \%$. IR $\left(\mathrm{cm}^{-1}\right)$ : 3328, 2913, 2345, 1608, 1375, 1311, 1246, 1132, 1093, 912, 789, 703, 650.

\subsection{Crystal Structure Determination}

Single-crystal X-ray diffraction data of ZTU-5 were collected on a Bruker with a Mercury CCD area detector (Mo- $K \alpha, \lambda=0.71073 \AA$ ). Empirical absorption corrections were applied to the data using the Crystal Clear program [16]. The structures of ZTU-5 were solved by direct methods and refined by full-matrix least-squares on $F^{2}$ using the SHELXTL-2017 program [17]. Metal cations were located from the $E$-maps and other non-hydrogen atoms were located in successive difference Fourier syntheses. All non-hydrogen atoms were refined anisotropically except for a few badly disordered atoms and the lattice solvent molecules. The organic hydrogen atoms were positioned geometrically with fixed thermal factors, while the coordinated water molecules were located using the difference Fourier method and refined freely. Crystallographic data and other pertinent information for ZTU-5 are summarized in Table 1, and the selected bond distances and bond angles are listed in Table S1. The CCDC number for ZTU-5 is 1950505.

Table 1. Crystal data and structure refinement for $\left[\mathrm{Tb}(\mathrm{Habtc})(\mathrm{DMSO})\left(\mathrm{H}_{2} \mathrm{O}\right)_{2}\right]_{n}(\mathbf{Z T U}-5)$.

\begin{tabular}{cc}
\hline Compounds & ZTU-5 \\
\cline { 2 - 3 } CCDC & 1950505 \\
Formula & $\mathrm{C}_{18} \mathrm{H}_{17} \mathrm{~N}_{2} \mathrm{O}_{11} \mathrm{STb}$ \\
Space group & 628.33 \\
$a(\AA)$ & $P \overline{1}$ \\
$b(\AA)$ & $7.7450(2)$ \\
$c(\AA)$ & $11.224(3)$ \\
$\alpha(\mathrm{deg})$ & $12.051(3)$ \\
$\beta(\mathrm{deg})$ & $78.901(6)$ \\
$\gamma(\mathrm{deg})$ & $82.678(7)$ \\
$V\left(\AA^{3}\right)$ & $85.359(6)$ \\
$\mathrm{Z}$ & $1017.9(4)$ \\
$D_{\mathrm{c}}\left(\mathrm{g} \mathrm{cm}^{-3}\right)$ & 2 \\
$M\left(\mathrm{~mm}^{-1}\right)$ & 2.050 \\
$F(000)$ & 3.644 \\
$\mathrm{GOF}^{a}$ & 616.0 \\
$R_{1}{ }^{a}$ & 1.062 \\
$w R_{2}{ }^{a}$ & 0.0175 \\
${ }^{a} R=\sum\left(\left\|\mathrm{F}_{\mathrm{o}}|-| \mathrm{F}_{\mathrm{c}}\right\|\right) / \sum\left|\mathrm{F}_{\mathrm{o}}\right|, w R=\left\{\sum w\left[\left(\mathrm{~F}_{\mathrm{o}}{ }^{2}-\mathrm{F}_{\mathrm{c}}{ }^{2}\right)^{2}\right] / \sum w\left[\left(\mathrm{~F}_{\mathrm{o}}{ }^{2}\right)^{2}\right]\right\}^{1 / 2} ;\left[\mathrm{F}_{\mathrm{o}}>4\left(\mathrm{~F}_{\mathrm{o}}\right)\right]$.
\end{tabular}




\section{Results and Discussion}

\subsection{Synthesis and Structure Description of the Crystal Structures}

The solvothermal reaction of the $\mathrm{Tb}\left(\mathrm{NO}_{3}\right)_{3} \cdot 6 \mathrm{H}_{2} \mathrm{O}$ and $\mathrm{H}_{4}$ abtc ligand in a mixed-solvent of DMSO and $\mathrm{H}_{2} \mathrm{O}(\mathrm{V} / \mathrm{V}=1: 1)$ led to one novel terbium tetracarboxylate framework (ZTU-5). ZTU-5 is crystallized in the triclinic space group $P \overline{1}$ with lattice parameters a = 7.7450(2) $\AA, b=11.224(3) \AA$, $\mathrm{c}=12.051(3) \AA, \alpha=78.901(6)^{\circ}, \beta=82.678(7)^{\circ}$, and $\gamma=85.359(6)^{\circ}$, and its asymmetry unit consists of one independent $\mathrm{Tb}(\mathrm{III})$ ion, one $\mathrm{Habtc}^{3-}$ ligand, two terminally coordinated water molecules, and one coordinated DMSO molecule (Figure 1a). The central $\mathrm{Tb}$ (III) ions are eight coordinated by five carboxylate $\mathrm{O}$ atoms from four different $\mathrm{Habtc}^{3-}$ ligands, two $\mathrm{O}$ atoms from two coordinated $\mathrm{H}_{2} \mathrm{O}$ molecules, and one $O$ atom from one coordinated DMSO molecule. The Habtc ${ }^{3-}$ ligand displays the $\mu_{2}-\kappa^{1}-\left(\kappa^{1}-\kappa^{1}\right)-\mu_{8}$ coordination mode (Figure $\left.1 \mathrm{a}\right)$ and two $\mathrm{Tb}$ (III) ions are linked by the bridging carboxylate from six $\mathrm{Habtc}^{3-}$ ligands, to generate the binuclear terbium SBUs with the $\mathrm{Tb}-\mathrm{Tb}$ distance of 5.3289(10) $\AA$ (Figure S1). The aromatic rings of two Habtc ${ }^{3-}$ ligands are arranged in an offset face-to-face mode with the parallel distance of 3.4531(26) $\AA$ (Figure 1b), which indicates the existence of weak $\pi-\pi$ stacking [18]. In addition, the binuclear terbium SBUs are bridged by the Habtc ${ }^{3-}$ ligands and extended into the 1D lanthanide-carboxylate chain (Figure 1c), which further expands into a 2D and 3D-supramolecular framework by the hydrogen bond interactions (Figure 1d and Table S2), involving O7-H7 $\cdots \mathrm{O} 3$ of the carboxylate groups and $\mathrm{O} 10-\mathrm{HB} \cdots \mathrm{O} 3, \mathrm{O} 11-\mathrm{H} 11 \mathrm{~B} \cdots \mathrm{O} 4$ between the pairs of water molecules and carboxylate groups.

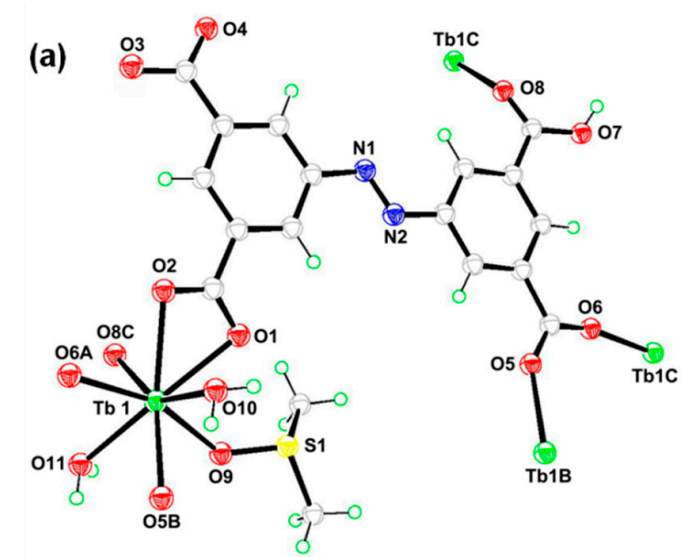

(c)
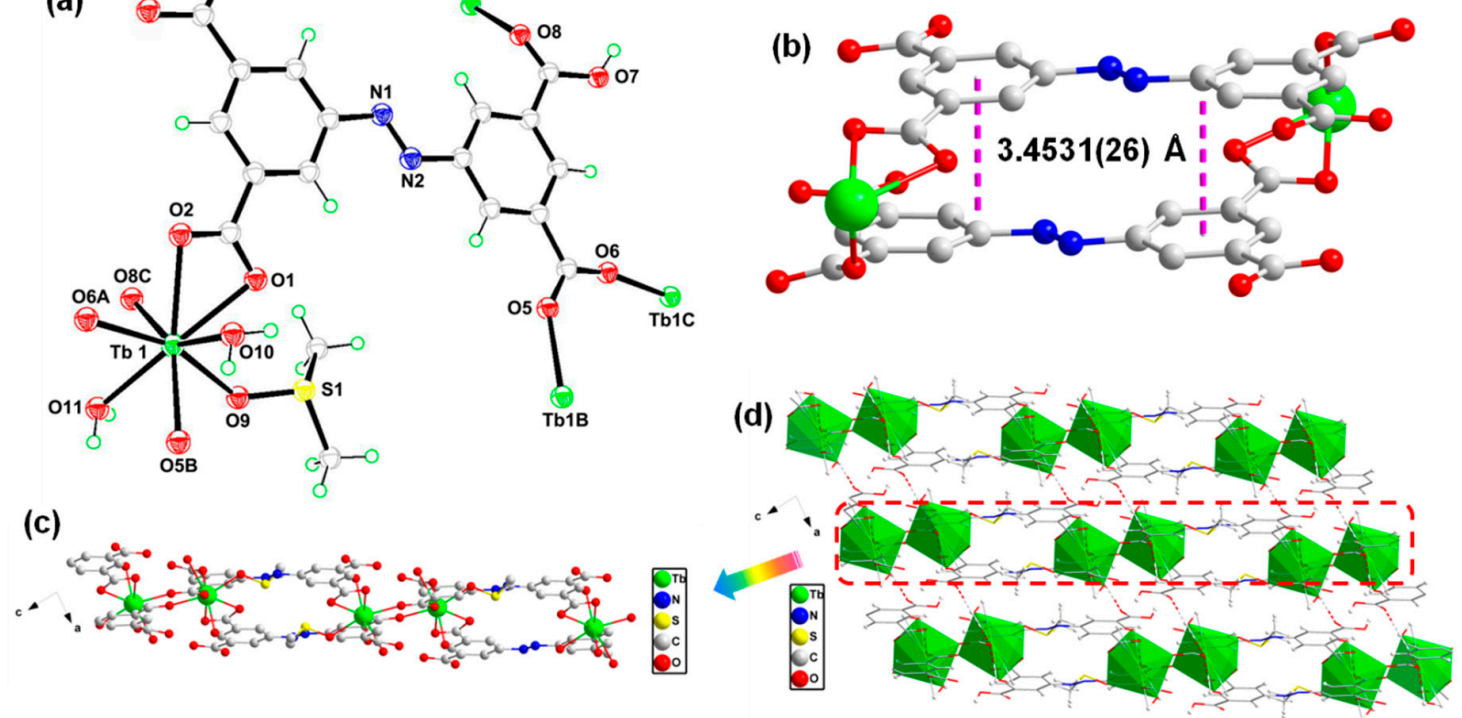

Figure 1. (a) Representation of the coordination environment of the $\mathrm{Tb}$ ion in $[\mathrm{Tb}$ (Habtc)(DMSO) $\left.\left(\mathrm{H}_{2} \mathrm{O}\right)_{2}\right]_{n}(\mathrm{ZTU}-5)$. Symmetry codes: A: $x+1, y, z-1 ; \mathrm{B}:-x,-y,-z+2 ; \mathrm{C}:-x,-y+1,-z+2 ; \mathrm{D}: x-1$, $y, z+1$. (b) The $\pi-\pi$ stacking interaction between aromatic rings of Habtc ${ }^{3-}$ ligands in ZTU-5. (c) and (d) The 1D lanthanide-carboxylate chain and 3D supramolecular architecture in ZTU-5.

\subsection{Hirshfeld Surface Analysis}

In order to study the intermolecular interactions in ZTU-5, the Hirshfeld surface analysis and 2D finger-printing were computed by the Crystal Explorer program [19]. As shown in Figure 2, the 3D hirshfeld surface mapped visually shows the interactions of crystal structure in ZTU-5; the red area denotes the strong interactions, which are attributed to the mostly hydrogen bonding including $\mathrm{O} \cdots \mathrm{H}$, but the electron density of the blue region is weak interactions [20].The significant interaction distribution mapped on the molecular surface of ZTU-5 was presented by the 2D fingerprint plots (Figure S2). The proportion of the $\mathrm{H}-\mathrm{H} / \mathrm{H}-\mathrm{H}, \mathrm{O}-\mathrm{H} / \mathrm{H}-\mathrm{O}, \mathrm{C}-\mathrm{H} / \mathrm{H}-\mathrm{C}, \mathrm{N}-\mathrm{H} / \mathrm{H}-\mathrm{N}$, and S-H/H-S interactions in 
the total Hirshfeld surface was 19.4\%, 26.8\%, 5.0\%, 1.7\%, and 1.0\%, respectively. These results indicated the intermolecular interactions are mainly derived from the $\mathrm{H}-\mathrm{H} / \mathrm{H}-\mathrm{H}$ and $\mathrm{O}-\mathrm{H} / \mathrm{H}-\mathrm{O}$ interaction [21].

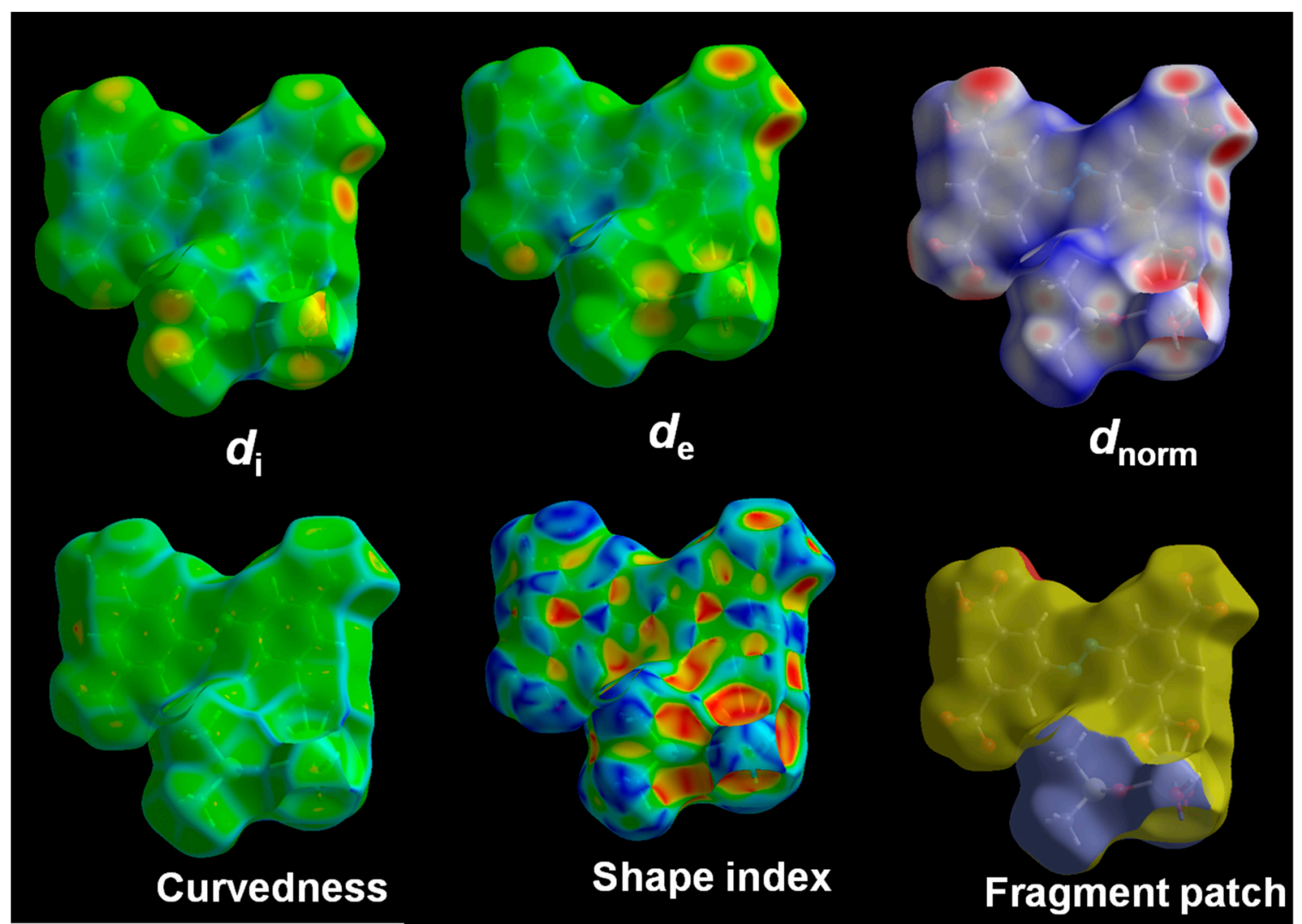

Figure 2. Hirshfeld surface mapped of $d_{\mathrm{i}}, d_{\mathrm{e}}, d_{\text {norm }}$, curvedness, shape index, and fragment patch in compound ZTU-5.

\subsection{XRD Patterns and Thermogravimetric Analyzer Data}

The XRD of ZTU-5 was performed to confirm its purity and structure, and all the peak positions on the curves for ZTU-5 are well matched with the simulated XRD patterns (Figure S3). In order to investigate the stability of ZTU-5 in solvent, the samples of ZTU-5 were immersed in DMF solution for $24 \mathrm{~h}$ at room temperature, and the XRD patterns of ZTU-5 are still consistent with the simulated ones, suggesting the stability of ZTU-5. In addition, ZTU-5 exhibits a weight loss of 18.03\% from 35 to $310^{\circ} \mathrm{C}$, which is attributed to the loss of one coordinated DMSO molecule and two coordinated water molecules (calcd. 18.16\%) (Figure S4).

\subsection{Magnetic Property}

The magnetic susceptibility of ZTU-5 was measured in the temperature range of 2-300 K under 1000 Oe. The $\chi_{m} T$ product for ZTU-5 is $23.36 \mathrm{~cm}^{3} \mathrm{~K} \mathrm{~mol}^{-1}$ at $300 \mathrm{~K}$, which is close to the expected theoretical value for two uncoupled $\mathrm{Tb}$ (III) ions $\left(23.65 \mathrm{~cm}^{3} \mathrm{~K} \mathrm{~mol}^{-1}\right.$ and $\left.\mathrm{g}=3 / 2,{ }^{7} \mathrm{~F}_{6}\right)$ [18]. Upon further cooling, the value of $\chi_{m} \mathrm{~T}$ sequentially decreases, reaching a minimum value of $16.20 \mathrm{~cm}^{3}$ $\mathrm{K} \mathrm{mol}^{-1}$ at $2 \mathrm{~K}$. In addition, the magnetic data were fitted by the Curie-Weiss equation, in order to obtain a Curie constant $\mathrm{C}=23.38 \mathrm{~cm}^{3} \mathrm{~K} \mathrm{~mol}^{-1}$ and Weiss temperature $\theta=-3.90 \mathrm{~K}$ (Figure S5). The decrease observed in the $\chi_{m} T$ value and the negative $\theta$ values suggest the presence of the weak anti-ferromagnetic interaction and other effects such as magnetic anisotropy and thermal depopulation of the $\mathrm{Tb}(\mathrm{III})$ excited states in ZTU-5 [22-24]. 


\subsection{Luminescence Property}

The solid state luminescence property of ZTU-5 was explored at room temperature, whichexhibits the typical emission peaks at 488.5, 542.5, 588.5, and $622.5 \mathrm{~nm}$ when excited at $308 \mathrm{~nm}$ (Figures S6 and S7), which are assigned to ${ }^{5} \mathrm{D}_{4} \rightarrow{ }^{7} \mathrm{~F}_{\mathrm{J}}(\mathrm{J}=6-3)$ transitions [25]. The strong luminescent emission band appears at $542.5 \mathrm{~nm}$, which arises from the ${ }^{5} \mathrm{D}_{4} \rightarrow{ }^{7} \mathrm{~F}_{5}$ transition. The band at $488.5 \mathrm{~nm}$ is attributed to the ${ }^{5} \mathrm{D}_{4} \rightarrow{ }^{7} \mathrm{~F}_{6}$ transition and the weaker emission bands at 588.5 and $622.5 \mathrm{~nm}$ correspond to the ${ }^{5} \mathrm{D}_{4} \rightarrow{ }^{7} \mathrm{~F}_{4}$ and ${ }^{5} \mathrm{D}_{4} \rightarrow{ }^{7} \mathrm{~F}_{3}$ transitions, respectively. In addition, the quantum yield and luminescence lifetime of ZTU-5 were measured at $25^{\circ} \mathrm{C}$, and the corresponding quantum yield and lifetime for ZTU-5 are $26.42 \%$ and $1.982 \mathrm{~ms}$, respectively.

Considering the good luminescent property of ZTU-5, the sensing of the antibiotics was performed through the luminescent detection. In order to explore the influence of different antibiotics in ZTU-5, metronidazole (MDZ), furazolidone (FZD), nitrofurantoin (NFT), nitrofurazone (NZF), ronidazole (RDZ), dimetridazole (DTZ), ornidazole (ODZ), and chloramphenicol (CAP) with different sizes and configurations were investigated (Figure S8). In a typical experiment, a $5 \mathrm{mg}$ sample of ZTU-5 was dispersed in $10 \mathrm{~mL}$ of different antibiotic in DMF solution (50 ppm) and processed into a suspension solution. Then, the resultant suspensions were monitored and the fluorescence intensity of these antibiotics showed the quench effect compared with the blank control sample, and the quenching efficiency (\%) was calculated by the absolute quantum yield ratio (Figure 3a). Particularly, the NZF solution exhibited a drastic quenching effect in ZTU-5, which indicated that ZTU-5 can act as a promising luminescent probe for the detection of NZF among various nitro-antibiotics [12-14]. In addition, the possible quenching mechanism was proposed as the collision interaction between the structures of ZTU-5 and nitro-antibiotics, consuming the energy transfer and resonance energy transfer, and leading to a reduced luminescent intensity [12-14]. Owing to the hydrogen bond interactions between ZTU-5 and NZF, as well as the conjugative effect of NZF, ZTU-5 exhibits highly selective and sensitive detection of NZF among various nitro-antibiotics.

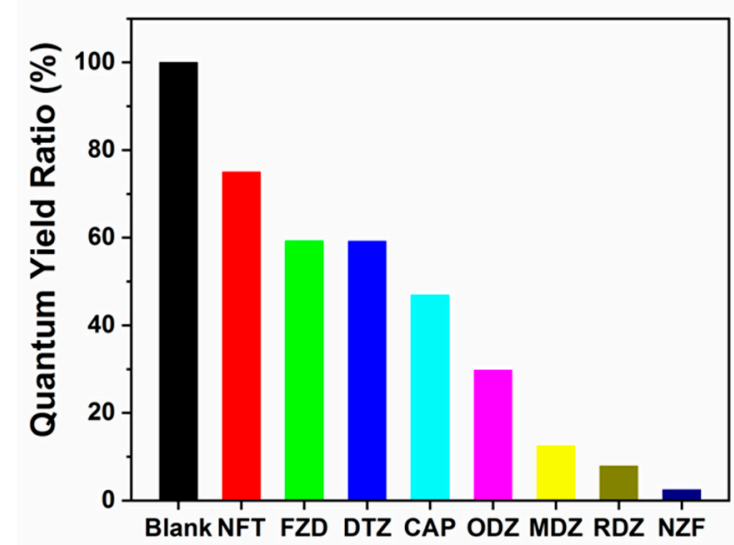

(a)

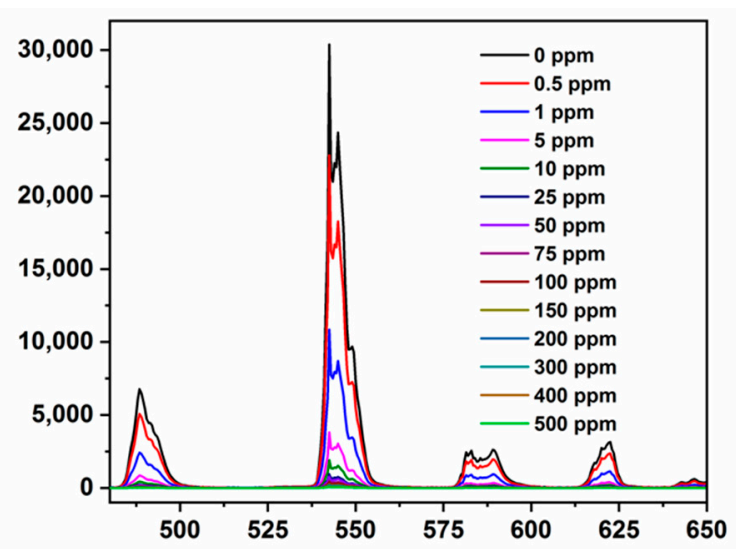

(b) Wavelength $(\mathrm{nm})$

Figure 3. (a) The quenching efficiency of ZTU-5 by the $50 \mathrm{ppm}$ concentrations of antibiotics in the DMF solution; (b) emission spectra of ZTU-5 in the DMF solution with the different concentrations of nitrofurazone (NZF). NFT, nitrofurantoin; FZD, furazolidone; DTZ, dimetridazole; CAP, chloramphenicol; ODZ, ornidazole; MDZ, metronidazole; RDZ, ronidazole.

For exploring the detection limit of ZTU-5 as the NZF probe, a series of concentrations of NZF solution were prepared (0.5-500 ppm) in DMF solution (Figure 3b). The luminescence intensity of ZTU-5 gradually decreased with the increasing concentration of NZF. The decreased luminescence intensity could be clearly observed when the ZTU-5 samples were immersed in a $0.5 \mathrm{ppm}$ of NZF solution. According to the Stern-Volmer equation, the quenching constants (Ksv) value is $8.12 \times$ $10^{3} \mathrm{M}^{-1}$ (Figure S9), which indicates a strong quenching effect of NZF in ZTU-5 with a good application 
prospect for the detection of NZF in DMF solution [12-14]. These results indicated that ZTU-5 exhibits highly selective and sensitive detection of NZF.

\section{Conclusions}

A novel terbium-tetracarboxylate framework (ZTU-5) with $\mathrm{H}_{4}$ abtc ligand was successfully synthesized and structurally characterized. ZTU-5 features a 2D-layered structure constructed by the binuclear terbium SBUs and abtc ${ }^{4-}$ ligand, which can be further expanded into a 3D-supramolecular framework by the hydrogen bond interactions. In addition, the magnetic and fluorescence properties of ZTU-5 are investigated and ZTU-5 exhibits high sensitivity and selectivity sensing for NZF nitro-antibiotics.

Supplementary Materials: The following are available online at http://www.mdpi.com/2073-4352/10/3/222/s1, Figure S1: The binuclear terbium secondary building units (SBUs) in ZTU-5, Figure S2: Hirshfeld surface mapped with the fingerprint plots of compound ZTU-5, Figure S3: The X-ray diffraction (XRD) patterns of ZTU-5, Figure S4: The thermo gravimetric analyzer (TGA) curves of ZTU-5, Figure S5: Dependence of $\chi_{\mathrm{m}} \mathrm{T}$ and $\chi_{\mathrm{m}}{ }^{-1}$ for ZTU-5, Figure S6: The solid-state excitation spectra of ZTU-5, Figure S7: The solid-state emission spectra of ZTU-5, Figure S8: Molecular structures of the explored nitro-antibiotics in this work, Figure S9: The linear correlation of $\left(\mathrm{I}_{0} / \mathrm{I}\right)$ vs. concentrations of NZF, Table S1: The selected bond distances and angles of ZTU-5, Table S2: Bond lengths $(\AA)$ and angles $\left(^{\circ}\right.$ ) of hydrogen bonds of ZTU-5.

Author Contributions: Y.S. and J.Q. conceived and designed the experiments, and contributed reagents/materials/ analysis tools; Y.S. performed the experiments; J.Z. and Z.Z. analyzed the data; Q.L. and Y.S. wrote the paper. All authors have read and agreed to the published version of the manuscript.

Funding: This work was supported by the National Natural Science Foundation of China (21861044), the Project funded by China Postdoctoral Science Foundation (2018M633426), and the Project funded by Yunnan Province Postdoctoral Science Foundation (2018).

Conflicts of Interest: The authors declare no competing financial interests.

\section{References}

1. Kümmerer, K. Antibiotics in the aquatic environment-A review. Chemosphere 2009, 75, 417-441. [CrossRef]

2. Homem, V.; Santos, L. Degradation and removal methods of antibiotics from aqueous matrices-A review. J. Environ. Manag. 2011, 92, 2304-2347. [CrossRef]

3. Yan, W.F.; Xiao, Y.; Yan, W.D.; Ding, R.; Wang, S.H.; Zhao, F. The effect of bioelectrochemical systems on antibiotics removal and antibiotic resistance genes: A review. Chem. Eng. J. 2019, 358, 1421-1437. [CrossRef]

4. Oberoi, A.S.; Jia, Y.Y.; Zhang, H.Q.; Khanal, S.K.; Lu, H. Insights into the Fate and Removal of Antibiotics in Engineered Biological Treatment Systems: A Critical Review. Environ. Sci. Technol. 2019, 53, 7234-7264. [CrossRef]

5. Ghirardinia, A.; Grillinia, V.; Verlicchi, P. A review of the occurrence of selected micro pollutants and microorganisms in different raw and treated manure-Environmental risk due to antibiotics after application to soil. Sci. Total Environ. 2020, 707, 13118.

6. Blasco, C.; Corcia, A.D.; Picó, Y. Determination of tetracyclines in multi-specie animal tissues by pressurized liquid extraction and liquid chromatography-tandem mass spectrometry. Food Chem. 2009, 116, 1005-1012. [CrossRef]

7. Moreno-González, D.; Lara, F.J.; Jurgovská, N.; Gámiz-Gracia, L.; García-Campana, A.M. Determination of amino glycosides in honey by capillary electrophoresis tandem mass spectrometry and extraction with molecularly imprinted polymers. Anal. Chim. Acta. 2015, 891, 321-328. [CrossRef]

8. Hakansson, K.; Coorey, R.V.; Zubarev, R.A.; Talrose, V.L.; Hakansson, P.J. Low-mass ions observed in plasma desorption mass spectrometry of high explosives. Mass Spectrom. 2000, 35, 337. [CrossRef]

9. Moros, J.; Laserna, J.J. New Raman-laser-induced breakdown spectroscopy identity of explosives using parametric data fusion on an integrated sensing platform. Anal. Chem. 2011, 83, 6275-6285. [CrossRef]

10. Tabrizchi, M.; ILbeigi, V. Detection of explosives by positive corona discharge ion mobility spectrometry. J. Hazard. Mater. 2010, 176, 692-696. [CrossRef]

11. Wang, P.L.; Xie, L.H.; Joseph, E.A.; Li, J.R.; Su, X.O.; Zhou, H.C. Metal-Organic Frameworks for Food Safety. Chem. Rev. 2019, 119, 10638-10690. [CrossRef] 
12. Wang, B.; Lv, X.L.; Feng, D.W.; Xie, L.H.; Zhang, J.; Li, M.; Xie, Y.B.; Li, J.R.; Zhou, H.C. Highly stable Zr (IV)-based metal-organic frameworks for the detection and removal of antibiotics and organic explosives in water. J. Am. Chem. Soc. 2016, 138, 6204-6216. [CrossRef]

13. Yu, M.K.; Xie, Y.; Wang, X.Y.; Li, Y.X.; Li, G.M. Highly Water-Stable Dye@Ln-MOFs for Sensitive and Selective Detection toward Antibiotics in Water. ACS Appl. Mater. Interfaces 2019, 11, 21201-21210. [CrossRef]

14. Hou, S.L.; Dong, J.; Jiang, X.L.; Jiao, Z.H.; Wang, C.M.; Zhao, B. Interpenetration-Dependent Luminescent Probe in Indium-Organic Frameworks for Selectively Detecting Nitrofurazone in Water. Anal. Chem. 2018, 90, 1516-1519. [CrossRef]

15. Joseph, L.; Jun, B.M.; Jiang, M.; Park, C.M.; Munoz-Senmache, J.C.; Hernández-Maldonado, A.J.; Heyden, A.; Yu, M.; Yoon, Y. Removal of contaminants of emerging concern by metal-organic framework nanoadsorbents: A review. Chem. Eng. J. 2019, 369, 928-946. [CrossRef]

16. Dolomanov, O.-V.; Bourhis, L.-J.; Gildea, R.-J.; Howard, J.A.-K.; Puschmann, H. OLEX2: A Complete Structure Solution, Refinement and Analysis Program. J. Appl. Cryst. 2009, 42, 339-341. [CrossRef]

17. Sheldrick, M. Crystal structure refinement with SHELXL. Acta Cryst. 2015, C71, 3-8.

18. Li, Q.P.; Du, S.W. Two novel 3D lanthanide supramolecular coordination polymers constructed from paddle wheel SBUs and hydrogen bonding: Synthesis, structures and properties. RSC Adv. 2014, 4, 30963-30967. [CrossRef]

19. Turner, M.J.; McKinnon, J.J.; Wolff, S.K.; Grimwood, D.J.; Spackman, P.R.; Jayatilaka, D.; Spackman, M.A. CrystalExplorer17. Available online: https://crystalexplorer.scb.uwa.edu.au (accessed on 27 February 2020).

20. McKinnon, J.J.; Spackman, M.A.; Mitchell, A.S. Novel tools for visualizing and exploring intermolecular interactions in molecular crystals. Acta Cryst. B. 2004, 60, 627-668. [CrossRef]

21. Spackman, M.A.; McKinnon, J.J. Fingerprinting Intermolecular Interactions in Molecular Crystals. CrystEngComm 2002, 4, 378-392. [CrossRef]

22. Li, Q.P.; Shen, Y.Q.; Wang, Y.; Ye, P.; Li, L.; Zhang, Z.J. Magnetic and Luminescence Properties of Two Dinuclear Lanthanide Complexes with Butterfly-like Arrangement. Z. Anorg. Allg. Chem. 2019, 645, 101-104. [CrossRef]

23. Zhang, P.; Zhang, L.; Wang, C.; Xue, S.F.; Lin, S.Y.; Tang, J.K. Equatorially coordinated lanthanide single ion magnets. J. Am. Chem. Soc. 2014, 136, 4484-4487. [CrossRef] [PubMed]

24. Li, Q.P.; Peng, Y.; Qian, J.J.; Yan, T.; Du, L.; Zhao, Q.H. A family of planar hexanuclear $\mathrm{Co}^{\mathrm{III}}{ }_{4} \mathrm{Ln}^{\mathrm{III}}{ }_{2}$ clusters with lucanidae-like arrangement and single-molecule magnet behavior. Dalton Trans. 2019, 48, 12880-12887. [CrossRef]

25. Li, Q.P.; Du, S.W. A family of 3D lanthanide organic frameworks with tunable luminescence and slow magnetic relaxation. RSC Adv. 2015, 5, 9898-9903. [CrossRef] 